\title{
CORRELATION BETWEEN CUSTOMER RELATIONSHIP MANAGEMENT SYSTEM USAGE, PRODUCT INNOVATION, AND CUSTOMER SATISFACTION
}

\author{
Wouroud ELFARMAWI \\ University of Phoenix, Tempe, Arizona, USA \\ e-mail: wouroud@email.phoenix.edu
}

\begin{abstract}
This quantitative correlational research examined the correlations between customer relationship management (CRM) usage, product innovation, and customer satisfaction. The general problem was the lack of evidence indicating the use of CRM system as effective in improving small- to medium-size companies' performance. Hence, the specific problem was to determine the beneficial use of a CRM system for customer satisfaction and product innovation. Data were gathered through surveymonkey.com. A total of 97 respondents were selected as sample from 10 small- to medium-size companies to answer the survey questions. Respondents were top managers, middle managers, and first-line managers of the selected organization. Statistics of the study were provided with the help of IBM Statistical Package for Social and Sciences version 23. The findings showed a strong correlation between the use of CRM system and customer satisfaction. They indicated the use of CRM system could improve the relationship with existing customers, could help attract prospective customers, and could win back former customers.
\end{abstract}

Keywords: correlation design, CRM system, customer satisfaction, product innovation, quantitative research.

JEL: M11, M15, O32, O33.

\section{Introduction}

As businesses acquired larger customer bases, the requirement to manage the relationships between business and customer became a challenge (Akroush, et al., 2011). This challenge provoked the evolution of technology to address this requirement through customer relationship management (CRM) system (Verrill, 2013). The CRM system initially started as a database to $\log$ in the contact information of customers and eventually grew into a more advanced management tool that improved business communication (Asghar, et al., 2013). The recent evolution of CRM system established features that increased the flexibility of tracking customers' expectations (Akroush, et al., 2011).

The potential of increasingly detailed customer records led to growing investments in CRM by US companies. Mavuram (2013) asserted that 73\% of the US companies have invested in CRM system to modernize their business. Yet, some business leaders still lack the belief that CRM system could affect customer satisfaction and increase their profitability (Colman, et al., 2011). Broetzmann, et al.
(2015) and Mavuram (2013), for example, discussed the reasons why most businesses find the CRM system hard to implement. The lack of resources in the scientific literature supporting the use of CRM system for these two purposes compounds the problem. The intent of the present research was to remedy this issue by investigating whether a correlation exists between the use of a CRM system and both customer satisfaction and product innovation.

This paper gathered information concerning the benefits of using a CRM system, particularly in smallto medium-size companies in the United States. The quantitative correlational design was used to determine whether the selected companies have benefited from the use of CRM system in satisfying their consumers' needs and improving their products. In this correlation, the predictor CRM system and the criterion variables of product innovation and customer satisfaction were evaluated to determine if the variables are interconnected with each other. The existing CRM Behavior Theories, which characterized the interrelated perspectives of CRM associated with the managing of customer satisfactions, 
were assessed to determine the link between them (Labus and Stone, 2010).

\section{Problem statement}

Before CRM system usage, forming a relationship with customers was a fairly complex process for companies (Mavuram, 2013). Theoretically, the CRM system would help businesses to understand their customers because it includes activities such as tracking customers' response to new products, which could prompt product improvement and innovation (Bovee and Thill, 2013, Darvish, et al., 2012; Ku, 2010). There is, however, a lack of empirical research indicating that the use of CRM system is efficient in enhancing small- to medium-size companies (Coltman, et al., 2011; Cuesta, 2014; Josiassen, et al., 2014). This problem was noted by Doyle (2012) and Gummesson (2014) who asserted that determining the beneficial use of a CRM system for product innovation and customer satisfaction was difficult.

Moreover, Chen and Popovich (2013) claimed that studying the relationship between CRM system usage and customer satisfaction should not be limited to satisfying customer desires, but must also extend to offering an ongoing healthy communication with the company. Doyle (2012) and Gummesson (2014) agreed on a need to prove the beneficial use of CRM system for product innovation and customer satisfaction.

\section{$3 \quad$ Research questions}

The study investigated the relationship among the three variables: CRM system usage, product innovation, and customer satisfaction. The quantitative correlational design was used to address the problem by answering the research questions and identifying the interaction between variables (Bettany-Saltikov and Whittaker, 2013). The study considered the hypotheses by detecting the existence of statistical correlations between the variables.

The first research question addressed whether the CRM system contributes to customer satisfaction with the company's products and services. The question examined whether the CRM system can provide critical information for the company to improve de- livery of quality products to the consumers, so as to improve business outcomes.

RQ1: What association, if any, is there between the use of a CRM system and satisfaction of customers for small- to medium-size companies in the United States?

The second research question examined whether using CRM systems contributes to product innovation with a view to meet customer expectation. During the decline stage of product life cycle, innovation is necessary to satisfy the changing and evolving needs of customers.

RQ2: What association, if any, is there between the use of a CRM system and product innovation for small- to medium-size companies in the United States?

\section{The hypotheses}

Correlation was used to accept or reject the hypotheses.

H1 $1_{0}$ : There is no significant association between the use of the CRM system and customer satisfaction for small- to medium-size companies in the United States.

$\mathrm{H1}_{\mathbf{a}}$ : There is a significant association between the use of the CRM system and customer satisfaction for small- to medium-size companies in the United States.

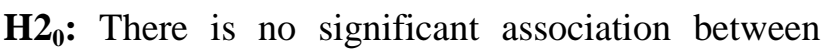
the use of the CRM system and product innovation for small- to medium-size companies in the United States.

$\mathbf{H} \mathbf{2}_{\mathbf{a}}$ : There is a significant association between the use of the CRM system and product innovation for small- to medium-size companies in the United States.

\section{$5 \quad$ Significance of the study}

The CRM system has generally been advocated as a powerful tool for progress (Hassan and Parvez, 2013). Yet, many of the hyped benefits have not been scientifically proven. This study about the use of CRM system in the small to medium-size US 
businesses can therefore be informative on a number of levels. Valuable information might be gathered in the business following categories:

\section{- Innovation}

This quantitative correlational design can impart information to increase product innovation. CRM system usage offers processes for generating new ideas into valuable products. The advantage of CRM system usage provides knowledge that is significant for product innovation so as to develop the company's financial benefit.

\section{- Leadership}

The present study result may encourage business owners to use CRM system in their organizations to help their leadership. CRM system allows leadership to develop their business practice by managing the relationship with their customers in order to help satisfy their needs.

\section{- Business organizations}

The present research can contribute to the literature of several schools of thought on diverse business strategy and customer service models, leading to higher customer retention and profit. Business organizations are still persuaded to adopt CRM system to create and manage their relationship with customers.

\section{- Customers}

The present study result may benefit the customers because it offers information that helps consumers determine their significant roles in the business. It helps generate a concern for customers as stakeholders and hence prompts businesses to establish effective communication between them. Businesses obtain better profitability, which stems from satisfying consumers.

\section{- Education}

The present study offered valuable theories that can be used as starting points by academicians in their discussions and debates. This research provides a base knowledge about the correlation between using a CRM system and customer satisfaction. Establishing a correlation between product innovation and the use of CRM system remains an open subject for further studies.

\section{Literature review}

As the trend of business modernization continued to progress, sellers and buyers lost their close relationships. Before Industrial Revolution, traders knew their customers well, understood their demands, and sometimes knew them by name. When mass production crept in, the wall between sellers and buyers was created. As a result, the first imperative became how to find customers for standardized products (Wang and Hui, 2012; Hailey, 2015).

Over the past years, the CRM system has evolved from different business programs. Using CRM system for medium-size businesses in the United States is becoming prevalent because of companies' interest in boosting their competitive advantages. The essential use of CRM system is to integrate technology and business process to satisfy the needs of customers (Bose, 2012). Ru-Jen, Rong-Huei and Kuan-Shun (2010) opine that, with the advancement of technology, the use of CRM system has the potential of facilitating companies-customer interaction. The objective is to deliver the required information to customers to create an effective communication (Ernst, et al., 2011).

CRM system has begun to make information more practicable by releasing solutions of newer software that were adaptable through industries (Ku, 2010; Hailey, 2015). Today, the CRM system is still employed by businesses that are dependent on two features: innovation and customer satisfaction (CRM Switch Staff, 2013). The CRM systems focused primarily on the needs of the consumers (Bovée and Thill, 2013). The CRM systems concentrate on one customer at a time, establishing a lasting relationship, and then build an equally beneficial relationship (Gummesson, 2014).

Some companies nowadays experience certain difficulty in furthering success in customer service. The main issue that they reason out is lack of human interaction because they render their services in the virtual platform. Josiassen, Assaf and Cvelbar (2014) asserted that the development of CRM system to advance innovations could be traced in the company's business system.

In the literature, outcome variables such as product innovation and customer satisfaction were directly 
linked with the CRM system. Using CRM allows corporate representatives to concentrate on one customer at a time, establishing first a lasting and then an equally beneficial relationship (Gummesson, 2014). In the early 21 st century, various companies are competing to establish a new connection with existing customers and raise long-term customer allegiance and profitability for their company (Chen and Popovich, 2013; Hailey 2015). A CRM strategy could strengthen existing customer's relations and create new ones (Wang and Hui, 2012).

The CRM system allows a coherent strategy that can maximize the relationships among the customers (Bovée and Thill, 2013). Knowing each customer by using a business strategy of customer-centric data mining techniques, the organization can consistently and proactively offer and sell better products or services for a longer period (Kindström and Kowalkowski, 2014). Besides the technological improvements, CRM system initiatives signify a mean change in weight from managing the portfolios of the product to managing the portfolios of the customers and requiring changes to business process.

\section{$7 \quad$ Method}

\subsection{Method and design}

The goal of the quantitative method with correlational design was to link the use of CRM system to product innovation and customer satisfaction in small- to medium-size companies in the United States. The use of quantitative correlational design helped discover a linear relationship between the predictor, CRM system usage, and criterion variables such as product innovation and customer satisfaction. The use of a quantitative method is to calculate the research data (Neuman, 2011; Vogt, 2003).

The nature of this study required data collection from primary sources. This task was accomplished by asking participants their opinions in a structured way to allow a production of statistical maps and facts to guide in explaining the issue under investigation (Nenty, 2009; Neuman, 2011). Information was gathered through SurveyMonkey electronic platform where participants from small- to medium-size American companies, which use CRM system, were selected to solicit information about their use of CRM. This approach resulted in a generalization gleaned from a sample population and the measurement of the different perceptions and opinions in a given cohort (Bettany-Saltikov and Whittaker, 2013).

\subsection{Setting, population, and sample}

The study population comprised of individuals working in the categories of top managers, middle managers, and first-line managers of small- to mediumsize US companies using the CRM system for product innovation and customer satisfaction. A total of 97 respondents were selected to answer the survey questions. All participants who agreed to participate in the survey were redirected to the survey form, whereas participants who disagreed received a word of thanks while their survey monkey session automatically closed. The minimum sample size of the participants was calculated using the statistical software $G^{*}$ Power version 3.1.9.2. The probability sampling method was used because it utilizes a form of random selection.

\subsection{Materials and instruments}

The instrument derives data from the responses to the survey (Black, 1999; Vogt, 2003). The questions focused on the participants' perceptions and expectations about the CRM system usage based on product innovation and customer satisfaction. The results of the study were tabulated based on participants' responses to the survey. All confidential information that pointed to the identity of participants was protected. No name of any participants was disclosed. Research quality revolves around the solution to a particular issue (Davies and Dodd, 2002). Incorporating trustworthiness through consistent procedures in this study suggested the validity and reliability of the collected data and data gathering were accurate and free of doubt.

\subsection{Data collection and analysis procedure}

After IRB approval, three volunteers served as pilot study participants from small- to medium-size organ- 
izations with knowledge and current use of CRM system. A pilot study became a necessity in research study using a survey crafted for gathering the data (Black, 1999). Pilot study participants were able to rate statements regarding CRM system usage and its relation to the two related variables. In the actual study, respondents were asked to sign an informed consent form. The survey comprised mostly of structured statements that the respondents rated from 1 to 5 , with 1 meaning strongly disagree and 5 strongly agree.

The data collected from SurveyMonkey were entered into the IBM SPSS version 23 and then the degree of the relationship was determined by tabulating the data in a frequency distribution table. The mean average for each statement was computed. In a Likert-style case, this research computed the total score for the scale; after that it was correlated with other continuous variables. The process of data analysis involved tabulating, classifying, and connecting the data with the context of the study. Pearson correlation was used to measure the linear relationship between CRM system usage (X) and product innovation $(\mathrm{Y})$ and between CRM system usage $(\mathrm{X})$ and customer satisfaction (Y). The results of these statistical analysis procedures were recorded so that they could be easily retrieved.

\section{$8 \quad$ Results of analysis}

The study findings articulated the ideas, opinions, and behavior of the participants to determine how the use of CRM system ascertains the relationship with customer satisfaction and product innovation. Data gathered from the 97 participants were classified into three different layers of positions. These were the top managers, middle managers, and first-line managers of the selected organizations. The survey participants served as a core for assessing the correlation between CRM system usage, product innovation, and customer satisfaction. Data gathered from the participants were used to determine how the use of CRM system establishes the relationship with product innovation and customer satisfaction. The researcher chose to analyze the data using the ordinal analysis, because the variables of this study are treated as continuous. Each variable is composed of six statements that the research participants rated from strongly agree to strongly disagree, using the Likert-scale model. The IBM SPSS version 23 helped determine the reliability of the data in this research study. Cronbach's alpha is a measure of internal consistency of scale reliability as shown in Table 1 .

Table 1. Cronbach's alpha parameters (Source: Authors' own research)

\begin{tabular}{|c|c|}
\hline Cronbach's Alpha & Internal Consistency \\
\hline$\grave{\alpha} \geq 0.9$ & Excellent \\
\hline $0.9 \geq \grave{\alpha} \geq 0.8$ & Good \\
\hline $0.8 \geq \grave{\alpha} \geq 0.7$ & Acceptable \\
\hline $0.7 \geq \grave{\alpha} \geq 0.6$ & Questionable \\
\hline $0.6 \geq \grave{\alpha} \geq 0.5$ & Poor \\
\hline
\end{tabular}

The first research question formed a correlation between CRM system usage and customer satisfaction by using Pearson correlation. Six statements under RQ1 served as the core for assessing the first two variables: the use of CRM system and customer satisfaction. There were two hypothesis derived from RQ1 for testing the acceptance or rejection, using the IBM SPSS version 23. The Pearson correlation coef- ficient $r$ takes a range of values from +1 to -1 . A value of 0 indicates that there is a negative correlation between the two variables. The standard deviation (std) showed that the data around the mean are concentrated. It is shown by smaller standard deviations of 11 and 6, respectively. The correlation coefficient (r) of .622 measures the strength and direction of a linear relationship between the CRM system and 
customer satisfaction that has a negative value lower than 1.0. The value of $r$ is continuously between +1 and -1 . It describes the correlation between the two variables. Customer satisfaction is exactly +1 , which means there is a perfect linear relationship with CRM system usage. The results led to the rejection of null hypothesis.

The second research question determined the correlation between CRM system and product innovation. Six statements were covered under RQ2. These pertained to the correlation between CRM system and product innovation. Two hypotheses were derived from RQ2 for testing the acceptance or rejection, using the IBM SPSS version 23. The standard deviation (std) showed that the data around the mean are concentrated. It is shown by smaller standard deviations of 113 and 129, respectively. The correlation coefficient ( $r$ ) of 0.371 measures the strength and direction of a linear relationship between the CRM system and product innovation, which has a value of 0.47. As a result, the Pearson correlation gave a negative value on the three variables. The value of 0 indicates that there is a negative association between the two variables. However, as the value of one variable decreases, the value of the other variable increases. As a result, the null hypothesis is also rejected.

The findings of this study showed that CRM system usage has a significant association with customer satisfaction. The perfect linear relation between CRM system and customer satisfaction is determined by a perfect positive linear relationship. On the other side, correlation between CRM system and product innovation has a negative linear relationship. This means that the decrease is in the linear relationship.

Table 2. Analysis of the research question (Source: Authors' own research)

\begin{tabular}{|l|c|c|c|c|c|}
\hline & $\mathrm{N}$ & Range & Mean & Std. Deviation & Variance \\
\cline { 2 - 6 } & Statistic & Statistic & Statistic & Statistic & Statistic \\
\hline Awareness & 97 & 4 & 4.00 & 1.146 & 1.313 \\
\hline Difficulty & 97 & 4 & 4.03 & 1.159 & 1.343 \\
\hline Acclaims & 97 & 4 & 3.95 & 1.014 & 1.029 \\
\hline Easy to use & 97 & 4 & 4.06 & 1.019 & 1.038 \\
\hline Accurate result & 97 & 4 & 3.96 & 1.030 & 1.061 \\
\hline Useful solution & 97 & 4 & 3.74 & 1.013 & 1.027 \\
\hline Service satisfaction & 97 & 4 & 4.14 & 0.890 & 0.791 \\
\hline Positive remarks & 97 & 4 & 4.12 & 0.949 & 0.901 \\
\hline Saying good things & 97 & 4 & 4.12 & 1.013 & 1.026 \\
\hline Customer loyalty & 97 & 4 & 4.04 & 1.050 & 1.102 \\
\hline Feeling rewarded & 97 & 4 & 4.01 & 1.015 & 1.031 \\
\hline Increased customers & 97 & 4 & 3.97 & 1.015 & 1.030 \\
\hline Product innovation & 97 & 4 & 4.01 & 1.046 & 1.094 \\
\hline New products & 97 & 4 & 4.09 & 1.032 & 1.064 \\
\hline New ideas & 97 & 4 & 3.72 & 1.125 & 1.265 \\
\hline Introduce more products & 97 & 4 & 4.01 & 1.123 & 1.260 \\
\hline Competitive new products & 97 & 4 & 4.01 & 1.015 & 1.031 \\
\hline Innovative products & 97 & 4 & 3.92 & 1.038 & 1.076 \\
\hline Valid N (listwise) & 97 & & & & \\
\hline
\end{tabular}


Discussion

In this quantitative correlation study, the three variables include CRM system usage, product innovation, and customer satisfaction. The purpose is to determine the correlation among these variables. The research questions were distributed randomly to selected participants from small- to medium-size companies in the United States. This process started after participants agreed to the informed consent (located at the very first page). Those who agreed were automatically guided to the survey instrument. The study results were collected and tabulated using the IBM SPSS version 23 to give the statistical computation of the study findings. The intent is to determine more precisely if the use of CRM system improves the operation of small- to medium-size organization in the United States.

The measurements under customer satisfaction involved customers expressing positive remarks about our organization, customers' satisfaction with our service, customers commending our services to their relatives and friends, customers remaining loyal to the organization, and customers feeling rewarded from their purchases in our company. The increase of the customer base is generally taken to signify their satisfaction with the organization's offerings. In contrast, measurements of product innovation examine whether our organization develops new products regularly, always seeks for new ideas, introduces more products to our customers, offers competitive new products to the market, gains competitive edge in product innovation, and offers innovative products to a variety of customers.

The core research problem was to determine the significance of CRM system usage to customer satisfaction and product innovation in the operation of small- to medium-size companies in the United States. Two subquestions reinforced the central research question. Each research question had statements which the participants rated using the Likertscale model.

RQ1: What association, if any, is there between the use of a CRM system and customer satisfaction for small- to medium-size companies in the United States?
The findings of this research showed that the use of CRM system has a significant association with customer satisfaction. There was a perfect linear relationship between CRM system and customer satisfaction. The result indicated that the use of CRM system in small- to medium-size company in the United States has a greater chance of delivering admirable customer service, which leads to satisfied customers.

In fact, on the four statements pertaining to customer satisfaction ("The customers are satisfied with our service," "The customers expressed positive remarks about our organization," "The customers feel rewarded from their purchases in our company," and "The increase of our customers signifies their satisfaction with us"), participants overwhelmingly responded positively. The rounded percentages were $63 \%, 83 \%, 75 \%$, and $73 \%$, respectively.

RQ2: What association, if any, is there between the use of a CRM system and product innovation for small- to medium-size companies in the United States?

The findings of the research showed that the correlation between CRM system and product innovation has a negative linear relationship and the effect is moderate. This only proved that the CRM system is mostly meant to deliver better customer service rather than offering the business organization with ideas for new products to advance to the market. The hypotheses of the study were:

H1 : There is no significant association between the use of the CRM system and customer satisfaction for small- to medium-size companies in the United States.

$\mathbf{H 1}_{\mathbf{a}}$ : There is a significant association between the use of the CRM system and customer satisfaction for small- to medium-size companies in the United States.

The null hypothesis is rejected stating that there is no significant association between the use of the CRM system and customer satisfaction for small- to medium-size companies in the United States. Because the value lower than 0 indicates a negative association, when the value of one variable decreases, values of the other variable increase. 
H2 20 $_{0}$ : There is no significant association between the use of the CRM system and product innovation for small- to medium-size companies in the United States.

H2 $\mathbf{a}$ : There is a significant association between the use of the CRM system and product innovation for small- to medium-size companies in the United States.

The null hypothesis is rejected asserting that there is a significant association between the use of the CRM system and product innovation for small- to mediumsize companies in the United States. The negative correlation defines that the value lower than 0 indicates a negative association; as the value of one variable decreases, values of the other variable increase.

The outcome of this study is a cooperation between the researcher and the management of small- to medium-size companies in the United States. The participants agreed that the use of CRM system has significant relation on customer satisfaction whereas showing a weak relationship on product organization. The collected data showed that the use of CRM system has significant relationship to customer satisfaction and more likely increases profitability of small- and medium-size companies.

The participants stated that the CRM system usage improved their approachability and provided a comprehensive outlook on the entire customer life cycle. The relation between CRM system and customer satisfaction is determined by a perfect positive linear relationship. The result of the study only proved that by using the CRM system, small- to medium-size companies in the United States have a greater chance of delivering commendable customer service, resulting in satisfied customers. On the other side, the study indicated a weak relationship on product organization. It showed that the correlation between CRM system and product innovation has a negative linear relationship.

The business community, the customers, and the academe may find this study significant and informative in the business process, mainly because this quantitative correlational study provides information about rich business practices to improve customer satisfaction. The study results also encourage managers and business owners to join their talents and leverage their competencies by introducing CRM system into their business. The CRM system permits leadership to develop their business performance by managing their relationship with customers and keep them satisfied.

Business organizations reflect innovation because it includes the intentional application of information, imagination, and creativity in deriving various values from resources. The CRM system offers practical processes for creating new ideas about the business cycle. This study provided direction to business organizations to increase profit and avert financial losses because of disorganized infrastructure and unsatisfied customers. It showed improved customer satisfaction and consequently retention. This is a modest contribution to the vast literature on different business strategies and customer service models. Business organizations of several sizes are still stimulated to foster CRM system to create and manage an effective relationship with their customers.

Furthermore, this research may help raise customers' awareness of their important position in the business process. This awareness could be harnessed for the benefit of both companies and customers, who can support the organizational efforts in establishing steady communication, which could serve them better. Finally, the results are significant to anyone desiring to create a healthy competition in the business environment.

This research was a result of collaboration between the researcher and the management of small- to medium-size companies in the United States. Results of the analysis helped to highlight the impact of CRM system application on business processes, especially with respect to customer satisfaction. The findings of this study suggest that the business community, business leadership, and customers may reap benefits from proper implementation of CRM systems:

\section{- Management}

The study result can be used to gauge the extent to which the management of small- to medium-size organizations in the United States is developing their business process by using CRM system. This may allow business organizations to develop competitive approaches in global marketplace to attract and 
maintain more customers, and thereby increase their margin of profit.

\section{- Stakeholders}

This study gives the company stakeholders definite motivations to pursue the use of CRM system in their organization to support all efforts that could boost the company's profitability. Stakeholders should recognize the need to create value-based business practice. To succeed in this, they must preserve the interest of employees, suppliers, customers, and communities.

\section{- Leadership}

The findings of this research recommend the use of CRM system for business leaders to have a clearer picture of their customers' interaction with their companies' products and services. CRM system has tools that assist business leaders to wittingly follow up with their customers by providing the information and methods necessary to realize the company's vision.

The challenge for future researcher is to pick up from where this current research finds limitations and use the data to resolve the limitation and provide more generalizable conclusions. Future researchers may also benefit from this research particularly in developing a greater understanding of CRM system and its impact on product innovation and customer satisfaction. The benefits of CRM system remain open for future researchers, and the current research provides critical insights and an analytical baseline.

It follows that the theoretical framework of this research remains open for critical discussion and analysis, providing an introductory argument for future research. Although the reliability of the data of this research has been confirmed through investigation of experts in the industry and tested using the Cronbach's alpha, further studies may reveal some shortcomings. Future research may do better by increasing the number of small- to medium-size companies in order to broaden the scope of the research and involve more respondents aside from the management level.

\section{$10 \quad$ References}

[1] Akroush, M.N., Dahiyat, S.E., Gharaibeh, H.S., and Abu-Lail, B., 2011. Customer Relationship Management Implementation. International Journal of Commerce \& Management, 21(2), pp.158-190, DOI: 10.1108/10569211111144355.

[2] Asghar, R.J., Aramoon, M.H. and Alimohammadi, A., 2013. Customer Relationship Management in Electronic Environment. The Electronic Library, 31(1), pp.119-130, DOI: 10.1108/02640471311299173.

[3] Bettany-Saltikov, J., Whittaker, V.J., 2013. Selecting the Most Appropriate Inferential Statistical Test for Your Quantitative Research Study. Journal of Clinical Nursing, 23, pp.1520-1531. DOI: 10.1111/jocn.12343.

[4] Bose, R., 2012. Customer Relationship Management: Key Components for IT Success. Industrial Management \& Data Systems, 102(2), pp.89-97. DOI: 10.1108/02635570210419636.

[5] Bovee, C.L., Thill, J.V., 2013. Business in Action ( $6^{\text {th }}$ ed.). Upper Saddle River, NJ: Prentice Hall.

[6] Chen, I.J., Popovich, K., 2013. Understanding Customer Relationship Management (CRM), Business Process Management Journal, 9(5), pp.672-688. DOI:10.1108/14637150310496758.

[7] Coltman, T., Devinney, T.M., Midgley, D.F., 2011. Customer Relationship Management and Firm Performance. Journal of Information Technology, 26(3), pp.205-219. DOI: 10.1057/jit. 2010.39 .

[8] Cuesta, F.A., 2014. Looking Beyond Quality Perceptions to Customer Satisfaction with Technology Performance-based Acquisition Services (Doctoral dissertation). Available from ProQuest Dissertations \& Theses. (UMI No. 3648807).

[9] CRM Switch Staff, 2013. A Brief History of Customer Relation Management. The CRM Switch. Retrieved from https://www.crmswitch. com/crm-industry/crm-industry-history/

[10] Darvish, H., Kafashzadeh, A.R., Ahmadnia, H., 2012. Studying the Customer Relationship Management: A Case Study at Persian Technology Firm. Economic Insights - Trends \& Challenges, 64(3), pp.1-18. DOI: 10.1018/14783360903250 514. 
[11] Doyle, S.M., 2012. Quality Service Delivery: A Case Study of Strategic Customer Relationship Management (Doctoral dissertation). Available from ProQuest Dissertations \& Theses. (UMI No. 3503070).

[12] Ernst, H., Hoyer, W.D., Krafft, M., Krieger, K., 2011. Customer Relationship Management and Company Performance: The Mediating Role of New Product Performance. Journal of the Academy of Marketing Science, 39(2), pp.290-306. DOI: $10.1007 / \mathrm{s} 11747-010-0194-5$.

[13] Gummesson, E., 2014. Return on Relationships (ROR): the Value of Relationship Marketing and CRM in Business-to-Business Contexts. Journal of Business \&amp; Industrial Marketing, 19(2), pp.136-148. DOI: 10.1108/08858620410524016.

[14] Hailey, V., 2015. A Correlation Study of Customer Relationship Management Resources and Retailer Omni Channel Strategy Performance (Doctoral dissertation). Available from ProQuest Dissertations \& Theses. (UMI NO. 3687831).

[15] Hassan, A., Parvez, M., 2013. A Comparative Case Study Investigating the Adoption of Customer Relationship Management (CRM): The Case of Tesco and Sainsbury's. International Journal of Managing Value and Supply Chains, 4(1), pp.1-10. DOI: 10.5121/ijmvsc.2013.4101.

[16] Kindström, D., Kowalkowski, C., 2014. Service Innovation in Product-Centric Firms: a Multidimensional Business model Perspective. Journal of Business \&amp; Industrial Marketing, 29(2), pp.96-111. DOI: 10.1108/JBIM-08-2013-0165.

[17] Ku, E.S., 2010. The Impact of Customer Relationship Management Through Implementation of Information Systems. Total Quality Management \& Business Excellence, 21(11), pp.10851102. DOI:10.1080/14783360903250514.

[18] Labus, M., Stone, M., 2010. The CRM Behavior Theory - Managing Corporate Customer Relationships in Service Industries. Journal of Database Marketing \& Customer Strategy Management, 17(3/4), pp.155-173. DOI: 10.1057/dbm.2010.17.

[19] Mavuram, S.R., 2013. Customer Relationship Management (Doctoral dissertation). Available from ProQuest Dissertations \& Theses Full Text. (UMI No. EP69083).

[20] Josiassen, A., Assaf, A.G., Cvelbar, L.K., 2014. CRM and the Bottom Line: Do all CRM Dimensions Affect Firm Performance?. International Journal of Hospitality Management, 36, pp.130136. DOI: 10.1016/j.ijhm.2013.08.005.

[21] Ru-Jen, L., Rong-Huei, C.K., Kuan-Shun, C., 2010. Customer Relationship Management and Innovation Capability: an Empirical Study. Industrial Management \& Data Systems, 110(1), pp.111-133. DOI: 10.1108/02635571011008434.

[22] Verrill, A., 2013. History of CRM Software. Retrieved from http://blog.softwareadvice.com/ articles/crm/history-of-crm-software-011/.

[23] Wang, Y., Hui, F., 2012. Customer Relationship Management Capabilities: Measurement, Antecedents and Consequences. Management Decision, 50(1), pp.115-129. DOI: 10.1108/0025174 1211194903 